\title{
Comparison of criteria derived by government and patients for evaluating general practitioner services
}

\author{
Colin Haigh Smith, David Armstrong
}

\begin{abstract}
A study was carried out to see whether patients' criteria of good health care in general practice were different from those of the government and doctors. A total of 711 patients in a semirural group practice evaluated the importance of 20 criteria describing different facets of care. Half the criteria were derived from Promoting Better Health (health education, easy to change doctors, all children vaccinated, health checks for adults and children under 5, regular screening for cancer, woman doctor available, doctor goes on courses, well decorated premises, convenient surgery times); the other 10 were taken from a preliminary interview study of 24 patients (staff friendly and know me, doctor listens and sorts out problems, same doctor for consultations, nurse on premises, appointments available within 48 hours, waiting time $<20$ minutes, small surgery premises, tests available at surgery). Questionnaires containing 10 pairs of criteria assigned by computer were drawn up and patients asked to give their preference in each pair. The number of times each criterion was preferred was scored and its comparative importance ranked. The three criteria most highly ranked by all patients were having a doctor who listens, having a doctor who sorts out problems, and usually seeing the same doctor (all criteria originated by patients). The three least highly valued were health education, being able to change doctor easily, and well decorated and convenient premises (all criteria originated by the government). The criteria originated by patients as a group scored significantly more highly than those originated by government as a group.
\end{abstract}

In a more competitive general practice environment, in which doctors will be more inclined to satisfy the wishes of patients, officially supported indicators of good quality care might not get the encouragement that the government and doctors think that they deserve.

\section{Introduction}

Ensuring the quality of care in the NHS has traditionally been the concern of the medical profession and health service managers. Recently, how-

Br Med f 1989;299:494-6 ever, this system has been criticised as tending, in a paternalistic way, to ignore the real interests of patients themselves. ' In response to this criticism the government has been keen to encourage more decisions being based on the consumer in the provision of health care, not least because this approach supports a wider commitment to the marketplace as the most effective means of ensuring the supply of good quality services.

In November 1987 the government produced a white paper entitled Promoting Better Health as the centrepiece of its policy towards primary health care. ${ }^{2}$ This document, in accord with the general thrust of government policy, encouraged the raising of standards of care in general practice through the increased participation of the consumer. It claimed that if general practice services were responsive to patients' demands the quality of care would be improved.

The document, however, also contained various proposals for improving primary health care that had as their basis not consumer demand but normative criteria of good quality care originating from both medical and government sources. For example, the recent policy of the Royal College of General Practitioners of encouraging health promotion and prevention of illness ${ }^{3}$ found full expression in the white paper's proposals to encourage such activities in general practice.

The problem with this two pronged strategy is that the aspects of good quality care that would be identified and promoted by consumer choice are not necessarily the same as those that would be supported by the normative view of the medical profession and government. In other words, if patients were given greater command over the provision of general practice services parts of general practice might be encouraged that would not be a high priority for either the government or the medical profession, and vice versa.

To investigate this possibility and to explore its implications in general practice a survey was carried out asking patients to evaluate the comparative importance of criteria of good quality care originated by consumers and by government.

\section{Methods}

Ten statements were derived from the government's white paper Promoting Better Health that contained the government's view of aspects of health care that should be encouraged. A set of alternative criteria were derived by asking a group of 24 patients after a routine consultation what they thought were the most important things about a general practice. These various statements were then reduced to 10 more general criteria (table I).

A questionnaire was devised that asked for the patient's age, sex, and year of completion of full time education and then offered 10 forced choice pairs of statements drawn from the above two lists. These
Children under 5 having their regular checks in surgery A woman doctor available

Doctors go on regular courses to stay up to date

Premises well decorated and convenient

Surgery times when patients want them
Staff you know personally

A doctor who is not hurried and listens

Usually the sorts out problems

A nurse working on the premises

Appointments available within 48 hours

Waiting time $<20$ minutes

Not too big a place

Most tests done on the premises 
pairs were selected by a computer program that picked out random pairs from the 20 statements. Thus a given questionnaire would be repeated on average only once in every 190 times, which ensured that each statement was exposed to every other statement the maximum number of times and that any combination of statements was as likely as any other.

The questionnaires were given to a group of patients drawn from a semirural group practice located near the Medway towns. Successive adult patients consulting their doctor in the practice during a period of a week were asked to complete a questionnaire by assessing each pair of statements and expressing a simple preference. The degree of importance attached to each statement by the respondents as a whole would then emerge from the number of times each statement was preferred.

TABLE II -Comparison of patients' preferences for criteria of good health care originated by patients and by government

\begin{tabular}{|c|c|c|c|c|}
\hline Crux of statement & $\begin{array}{l}\text { No of } \\
\text { wins }\end{array}$ & $\begin{array}{l}\text { No of } \\
\text { losses }\end{array}$ & $\%$ Wins & Rank \\
\hline \multicolumn{5}{|c|}{ Criteria originated by patients } \\
\hline Staff friendly & 356 & 246 & 59 & 7 \\
\hline Staff know me & 308 & 291 & 51 & 9 \\
\hline Doctor listens & 488 & 112 & 81 & 1 \\
\hline Doctor sorts out problems & 443 & 159 & 74 & 2 \\
\hline Usually same doctor & 420 & 185 & 69 & 3 \\
\hline Nurse on premises & 275 & 328 & 46 & 13 \\
\hline Appointment within 2 days & 391 & 208 & 65 & 4 \\
\hline Waiting time $<20 \mathrm{~min}$ & 288 & 317 & 48 & 11 \\
\hline Small place & 287 & 315 & 48 & 12 \\
\hline Tests at surgery & 353 & 251 & 58 & 8 \\
\hline Total & 3609 & 2412 & $60^{\star}$ & \\
\hline
\end{tabular}

\begin{tabular}{lcccc}
\hline & Criteria originated by government & & \\
Health education & 159 & 445 & 26 & 18 \\
Change doctor easily & 140 & 467 & 23 & 19 \\
Every child immunised & 227 & 365 & 38 & 17 \\
Health checks for adults & 372 & 235 & 61 & 6 \\
Regular screening for cancer & 369 & 225 & 62 & 5 \\
Health checks for children & 257 & 345 & 43 & 15 \\
Woman doctor available & 264 & 341 & 44 & 14 \\
Doctor goes on courses & 302 & 302 & 50 & 10 \\
Well decorated premises & 92 & 511 & 15 & 20 \\
Convenient surgery times & 244 & 356 & 41 & 16 \\
\hline Total & 2426 & 3592 & 40 & \\
\hline
\end{tabular}

${ }^{\star}$ Difference between criteria originated by government and patients: $\chi^{2}=464 \cdot 2, p<0 \cdot 0001$

TABLE III-Comparison by sex of patients' preferences for criteria of good health care originated by patients and by govermment

\begin{tabular}{|c|c|c|c|c|}
\hline \multirow[b]{2}{*}{ Crux of statement } & \multicolumn{2}{|l|}{ Men } & \multicolumn{2}{|c|}{ Women } \\
\hline & $\begin{array}{c}\% \text { Of wins } \\
\text { (wins/encounters) }\end{array}$ & Rank & $\begin{array}{c}\% \text { Of wins } \\
\text { (wins/encounters) }\end{array}$ & Rank \\
\hline \multicolumn{5}{|c|}{ Criteria originated by patients } \\
\hline Staff friendly & $62(120 / 193)$ & 6 & $58(226 / 393)$ & 7 \\
\hline Staff know me & $52(97 / 188)$ & 10 & $52(203 / 393)$ & 10 \\
\hline Doctor listens & $85(160 / 188)$ & 1 & $80(315 / 395)$ & 1 \\
\hline Doctor sorts out problems & $81(154 / 190)$ & 2 & $70(273 / 393)$ & $2^{\star \star}$ \\
\hline Usually same doctor & $72(138 / 193)$ & 3 & $68(271 / 396)$ & 3 \\
\hline Nurse on premises & $42(80 / 191)$ & 14 & $47(184 / 395)$ & 13 \\
\hline Appointment within 2 days & $62(117 / 188)$ & 5 & $67(265 / 393)$ & 5 \\
\hline Waiting time $<20 \mathrm{~min}$ & $56(107 / 192)$ & 9 & $44(172 / 394)$ & $15^{\star \star \star}$ \\
\hline Small place & $45(85 / 189)$ & 13 & $49(193 / 396)$ & 11 \\
\hline Tests at surgery & $59(112 / 190)$ & 7 & $58(227 / 395)$ & 8 \\
\hline Total & $62(1170 / 1902)$ & & $59(2329 / 3943)$ & \\
\hline \multicolumn{5}{|c|}{ Criteria originated by government } \\
\hline Health education & $30(56 / 188)$ & 17 & $24(97 / 397)$ & 18 \\
\hline Change doctor easily & $24(46 / 190)$ & 18 & $22(89 / 397)$ & 19 \\
\hline Every child immunised & $34(64 / 186)$ & 16 & $41(158 / 388)$ & 16 \\
\hline Health checks for adults & $65(127 / 195)$ & 4 & $60(236 / 393)$ & 6 \\
\hline Regular screening for cancer & $51(96 / 188)$ & 11 & $68(264 / 390)$ & $4^{\star \star \star}$ \\
\hline Health checks for children & $37(70 / 188)$ & 15 & $45(179 / 396)$ & 14 \\
\hline Woman doctor available & $22(41 / 190)$ & 19 & $54(212 / 395)$ & $9^{\star \star \star \star}$ \\
\hline Doctor goes on courses & $57(108 / 188)$ & 8 & $48(189 / 398)$ & $12^{\star}$ \\
\hline Well decorated premises & $17(33 / 190)$ & 20 & $14(54 / 394)$ & 20 \\
\hline Convenient surgery times & $48(92 / 191)$ & 12 & $38(148 / 392)$ & $17^{\star}$ \\
\hline Total & $39(733 / 1894)$ & & $41(1626 / 3940)$ & \\
\hline
\end{tabular}

${ }^{\star}$ Differences between men and women by $\chi_{.}^{2}$ test: ${ }^{\star} \mathrm{p}<0 \cdot 05,{ }^{\star \star} \mathrm{p}<0 \cdot 01,{ }^{\star \star \star} \mathrm{p}<0.001$.
The statements were marked by comparing each pair and scoring the "winning" statement. This is similar in principle to a football league: at the end of the season the teams are ranked according to which team has won the most often. How much better one team is than another is in proportion to how many times each team has won. Similarly, the number of times each statement won (was preferred) was compared with the number of times each of the others won, and the statements were ranked for their comparative importance.

\section{Results}

In all, 711 adult patients were seen during the week of the survey. Sixty one patients failed to take a questionnaire and 25 failed to return one, giving an overall response rate of $88 \%$. Data on the age and sex of non-respondents were obtained and compared with similar data on those who responded. No significant differences were found between respondents and nonrespondents.

The results of the questionnaire are given in table II. Each statement was scored for its wins and losses and the results ranked. In addition, to assess the overall difference between the criteria originated by patients and those originated by government total wins and losses in each group were compared with the $\chi^{2}$ test.

The results were compared by sex and according to whether patients were aged 66 or more because of elderly people's higher use of the health services. As well as ranking all the statements for each subgroup specific differences were examined by calculating a $\chi^{2}$ test on the wins and losses for each individual statement. Significant differences are given in tables III and IV.

\section{Discussion}

Our results suggest that certain criteria of good quality practice supported by the medical profession and government are not highly valued by patients in this practice. Only health checks for adults and regular checks for cancer (breast and cervical screening) found widespead support; other criteria oriented towards the consumer, such as the ability to change a general practitioner readily, and health promotion activities, such as immunisation and health education, were not rated highly. Therefore, in this practice at least, the best way of maintaining patients' satisfaction seems to be to emphasise the traditional if more intangible virtues of good general practice encapsulated in the attentive, competent, and available doctor.

Yet it is also clear that giving priority to certain services over others will not necessarily satisfy all patients: we found differences between groups of patients, as tables III and IV show. The greater preference of female patients for a woman doctor to be available is not unexpected. Equally, women's preferences for screening tests for cancer probably reflects the availability of cervical smear tests and the publicity surrounding mortality from breast cancer. Male patients seemed more concerned with access in that they gave greater weight to length of waiting time and to convenient surgery hours. They also seemed more concerned with the standards of medicine in valuing more a doctor who can sort out problems and a doctor who goes on courses.

Older people gave greater priority to seeing the same doctor, being recognised by staff, and having a nurse available than did younger patients; younger patients, on the other hand, valued more highly health checks, screening for cancer, and immunisation for children. Overall, there seemed less conflict between the priorities of consumers and those of government among 
TABLE IV-Comparison by age of patients' preferences for criteria of good health care originated by patients and by govermment

\begin{tabular}{|c|c|c|c|c|}
\hline \multirow[b]{2}{*}{ Crux of statement } & \multicolumn{2}{|l|}{$\leqslant 65$} & \multicolumn{2}{|l|}{$\geqslant 66$} \\
\hline & $\begin{array}{c}\% \text { Of wins } \\
\text { (wins/encounters) }\end{array}$ & Rank & $\begin{array}{c}\% \text { Of wins } \\
\text { (wins/encounters) }\end{array}$ & Rank \\
\hline \multicolumn{5}{|c|}{ Criteria originated by patients } \\
\hline $\begin{array}{l}\text { Staff friendly } \\
\text { Staff know me } \\
\text { Doctor listens } \\
\text { Doctor sorts out problems } \\
\text { Usually same doctor } \\
\text { Nurse on premises } \\
\text { Appointment within } 2 \text { days } \\
\text { Waiting time }<20 \text { min } \\
\text { Small place } \\
\text { Tests at surgery }\end{array}$ & $\begin{array}{l}58(300 / 517) \\
\cdot 48(248 / 516) \\
82(424 / 517) \\
72(374 / 519) \\
67(348 / 520) \\
42(217 / 517) \\
66(341 / 516) \\
48(248 / 517) \\
46(239 / 520) \\
57(295 / 517)\end{array}$ & $\begin{array}{r}7 \\
10 \\
1 \\
2 \\
3 \\
15 \\
5 \\
11 \\
12 \\
8\end{array}$ & $\begin{array}{l}66(56 / 85) \\
71(59 / 83) \\
80(66 / 83) \\
81(67 / 83) \\
84(71 / 85) \\
65(56 / 86) \\
63(52 / 83) \\
46(40 / 88) \\
56(46 / 82) \\
66(57 / 87)\end{array}$ & $\begin{array}{l}5 \\
4^{\star \star \star} \\
3 \\
2 \\
1^{\star \star \star} \\
7^{\star \star \star} \\
8 \\
11 \\
10 \\
6\end{array}$ \\
\hline Total & $59(3034 / 5176)$ & & $67(570 / 845)$ & \\
\hline \multicolumn{5}{|c|}{ Criteria originated by government } \\
\hline $\begin{array}{l}\text { Health education } \\
\text { Change doctor easily } \\
\text { Every child immunised } \\
\text { Health checks for adults } \\
\text { Regular screening for cancer } \\
\text { Health checks for children } \\
\text { Woman doctor available } \\
\text { Doctor goes on courses } \\
\text { Well decorated premises } \\
\text { Convenient surgery times }\end{array}$ & $\begin{array}{l}28(146 / 522) \\
22(115 / 522) \\
40(205 / 513) \\
62(321 / 518) \\
66(338 / 512) \\
46(239 / 519) \\
43(223 / 518) \\
52(270 / 520) \\
14(73 / 518) \\
42(216 / 514)\end{array}$ & $\begin{array}{r}18 \\
19 \\
17 \\
6 \\
4 \\
13 \\
14 \\
9 \\
20 \\
16\end{array}$ & $\begin{array}{l}18(15 / 82) \\
28(24 / 85) \\
27(21 / 79) \\
57(51 / 89) \\
35(29 / 82) \\
22(18 / 83) \\
46(40 / 87) \\
38(32 / 84) \\
24(20 / 85) \\
33(28 / 86)\end{array}$ & $\begin{array}{l}20 \\
16 \\
17^{\star} \\
9 \\
14^{\star \star \star} \\
19^{\star \star \star} \\
11 \\
13^{\star} \\
18^{\star} \\
15^{\star}\end{array}$ \\
\hline Total & $41(2146 / 5176)$ & & $33(278 / 842)$ & \\
\hline
\end{tabular}

${ }^{\star}$ Differences between patients aged $\leqslant 65$ and those aged $\geqslant 66$ by $\chi_{.}^{2}$ test: ${ }^{\star} p<0 \cdot 05,{ }^{\star \star} p<0 \cdot 01,{ }^{\star \star \star}<0 \cdot 001$.

younger patients than among those aged 66 or more.

Some of the discrepancy between criteria originated by government and those originated by patients might reflect the fact that the criteria derived by government are specific and easily measured, whereas those derived by patients are more general and tend to overlap: " $\mathrm{A}$ doctor who sorts out problems" seems similar to "A, doctor who is not hurried and listens." Nevertheless, the criteria originated by patients have some validity in that they are derived from what patients themselves reported and patients were able to distinguish in their scoring between apparently similar criteria, as is shown, for example, by the difference between men and women in rating the importance of the doctor's ability to sort out problems.

Our sample was drawn only from attenders; a better sampling frame might have been all the patients on the list. Certainly some patients may not be consulting their doctor because some of the facilities on the government's list of criteria are not provided, but they are probably only a few.

Equally, some of the preferences expressed by patients in our study may reflect the particular services that they already experience in the practice. For example, the low priority given to well decorated premises probably indicates satisfaction with current arrangements: if the premises needed decorating then more concern might have been expressed about the importance of this criterion. Even so, a proper comparison of these criteria from the point of view of providing a service would entail calculating the costs of implementation. Poor decoration may have low priority with patients but it may be remedied comparatively cheaply, whereas consulting the same doctor may be highly valued but might be extremely difficult to arrange.

Given the probable influence of existing services and patients' expectations on the criteria that patients chose as important, some of our results may not be applicable to other practices. Many of our results, however, are supported by those of other studies of the satisfaction of patients in general practice, ${ }^{4-6}$ and the general thrust of the findings - that professional definitions of need and patients' own views may not be in exact accord-is probably applicable to other practices.

In a competitive climate this practice, like others, would have to attend to the current concerns of patients. Our results suggest that the realisation of good quality primary care as defined by the medical profession and government does not seem to be a central part of any package to maintain the satisfaction of patients. There seem to be limits to both consumer sovereignty and professional authority in influencing the good practices of the future.

This paper is based on a project completed as part of CHS's MSc in general practice at the united medical and dental schools.

1 Green DG. Working-class patients and the medical establishment. London Gower/Temple Smith, 1985 .

2 Department of Health and Social Security. Promoting better health. London: HMSO, 1987

3 Royal College of General Practitioners. Promoting prevention. London: RCGP, 1983. (Occasional paper No 22.)

4 Cartwright A, Anderson R. General practice revisited. London: Tavistock, 1981 Marsh G, Kaim-Caudle P. Team care in general practice. London: Croom Helm, 1976.

6 Consumer Association. Making your doctor better. Which? May 1987.

(Accepted 14 fune 1989

\section{MATERIA PARAMEDICA}

\section{Can you hear me, Eustace?}

The tubes that connect the throat with the middle ears, named Eustachian after Bartolomeus Eustachius (1563), are closed in the resting state. The tubes are opened by contraction of the salpingopharyngeal muscles, whereby a direct channel of air is established between the atmosphere (via the throat) and the middle ear. The pressure of air in the middle ear then changes to atmospheric if it was previously above or below that level. The tubes usually open during swallowing, which is why the air hostess may offer you a sweet to suck when the pressure in the plane falls and your eardrums bulge uncomfortably. They also open at the beginning of a yawn, and since yawning frequently occurs in circumstances that are quieter than those of an aircraft in flight, you may actually hear them open with a click. The lining of the tubes is moist, and when the walls separate during the opening process the stickiness derived from surface tension ensures a click, or rather a series of clicks within the space of a quarter second.

There are several other craniofacial movements that occur in association with various acts or emotional expressions, with which I am not now directly concerned, but which are worthy of mention to complete the picture: eyelid retraction, in response to surprise or fear; retraction of the alae nasi and widening of the nostrils in severe dyspnoea during inspiration; flattening of the ears against the head from contraction of the posterior auricular muscles, in response to surprise - to name a few. Now, some of these actions can be performed deliberately and in isolation from the above mentioned provocations. Thus, most actors can retract the eyelids. Some gifted individuals can amuse their nephews by rhythmically flattening (wiggling) the ears, and a few gifted persons can retract the alae nasi when requested. And this brings me, at last, to the act of opening the Eustachian tubes.

It can be done as an isolated act. Of course, you cannot observe the act, but the click can be heard by an observer who places his ear a few inches from one of the performer's ears. It can be recorded loud and clear by placing a microphone against the external auditory meatus. The capacity to open one's Eustachian tubes as an isolated act has its occasional uses. There are times when, for some reason or other-for example, an unusually hard nose blowing - the middle ear air pressure is raised, causing discomfort and slight impairment of hearing.

There are some curious aspects to this physiological phenomenon. Firstly, you can either do it or you cannot. If you cannot, you will probably react to the above preamble with boredom, incredulity, or non-comprehension. If you can, you will have taken entirely for granted your capacity to perform the act. Secondly, the capacity may be inherited.

I must now declare my personal interest. I can "click" my ears, and have been able to do so since childhood. My mother could, and my son can. My wife and daughter cannot. Is this a rare or common, if somewhat useless, accomplishment? --BERNARD J FREEDMAN 